\title{
INFLUÊNCIA DOS PNEUS NO CONSUMO DE COMBUSTÍVEL DE VEÍCULOS PESADOS
}

\author{
Eduardo Zaccai ${ }^{1}$, Erick B. Rodrigues ${ }^{1}$, Antonio Marcelo N. Moreno ${ }^{1}$ \\ ${ }^{1}$ Pirelli Pneus Ltda. \\ E-mails: Eduardo.zaccai@ pirelli.com, Erick.rodrigues@pirelli.com, \\ Marcelo.moreno@pirelli.com
}

\begin{abstract}
RESUMO
Os pneus contribuem de forma significativa no consumo de combustível dos veículos. Porém, com todas as variáveis envolvidas e fatores operacionais externos, a mensuração da sua contribuição torna-se um desafio complexo para os pesquisadores e engenheiros automotivos. Dada à tendência global dos programas governamentais em prol da sustentabilidade, que impulsiona a busca por redução do consumo de combustível dos veículos comerciais, e a nova legislação de etiquetagem dos pneus, o fator resistência ao rolamento torna-se cada vez mais importante para a indústria de pneumáticos. Este artigo visa avaliar a real influência dos pneus no consumo de combustível de um veículo comercial extrapesado, utilizando diferentes versões de pneus, a fim de analisar a correlação entre os resultados obtidos em testes de laboratório, testes experimentais realizados em ambiente controlado e simulações em softwares de dinâmica veicular com implementação de modelos matemáticos de resistência ao rolamento dos pneus.
\end{abstract}

\section{INTRODUÇÃO}

Esse trabalho tem dois objetivos principais, sendo o primeiro avaliar e quantificar como o consumo de combustível de um veículo pesado é afetado pela classificação de resistência ao rolamento dos pneus.

O segundo objetivo é avaliar a aplicação de um software de dinâmica veicular e validar a possibilidade de obter-se resultados representativos e quantificáveis de consumos de combustível. O que proporciona maior agilidade e versatilidade, reduzindo-se o custo para obtenção da contribuição da resistência ao rolamento no consumo de combustível.

Para atender a uma tendência do mercado, às novas legislações visando a redução da emissão de poluentes e aumento da eficiência energética, crescem as pesquisas e desenvolvimentos com este foco.

Atendendo-se à portaria INMETRO 544/12, será obrigatório que pneus de veículos de passageiros e veículos comerciais sejam comercializados com uma etiqueta que passa a vigorar de acordo com a linha do tempo apresentada na Figura 1. 


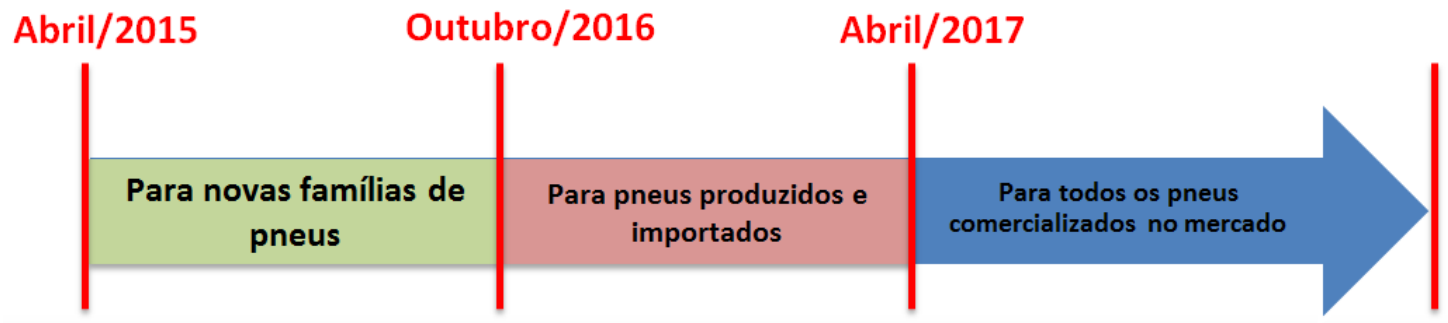

Figura 1 - Linha do tempo de implementação da portaria INMETRO 544/12

Assim, todos os pneus produzidos no Brasil a partir de outubro de 2016 deverão ser etiquetados, conforme Figura 2, com três critérios de eficiência: resistência ao rolamento, aderência em pista molhada e emissão de ruído.

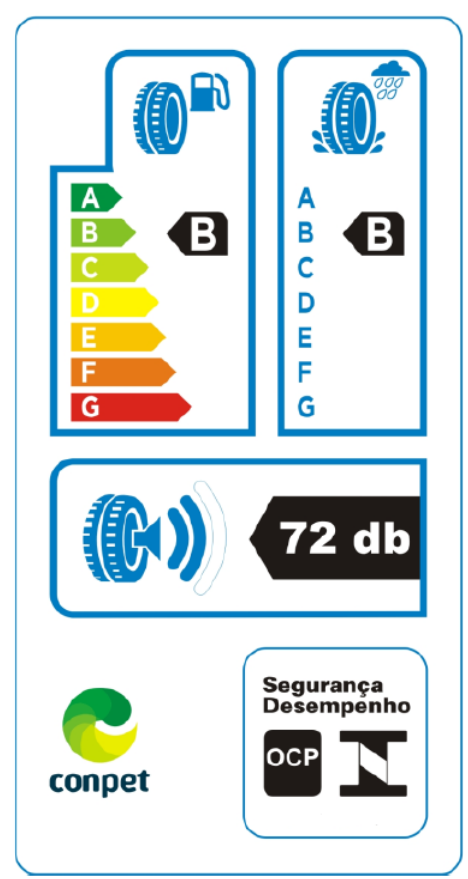

Figura 2 - Exemplo Etiqueta

Para pneus de veículos comerciais, a classificação de resistência ao rolamento é dividida em cinco classes, conforme Tabela 1:

Tabela 1- Classificação de Resistência ao Rolamento

\begin{tabular}{|c|c|}
\hline $\begin{array}{c}\text { Coeficiente de Resistencia ao Rolamento (CCR) } \\
\text { (kg/ton) }\end{array}$ & $\begin{array}{c}\text { Classificação de Eficiência } \\
\text { Energética }\end{array}$ \\
\hline $\mathrm{RRC} \leq 4,0$ & $\mathrm{~A}$ \\
\hline $4,1 \leq \mathrm{RRC} \leq 5,0$ & $\mathrm{~B}$ \\
\hline $5,1 \leq \mathrm{RRC} \leq 6,0$ & $\mathrm{C}$ \\
\hline $6,1 \leq \mathrm{RRC} \leq 7,0$ & $\mathrm{D}$ \\
\hline $7,1 \leq \mathrm{RRC} \leq 8,0$ & $\mathrm{E}$ \\
\hline
\end{tabular}




\section{RESISTÊNCIA AO ROLAMENTO}

Schuring [1] define resistência ao rolamento da seguinte forma: Resistencia ao rolamento é a conversão da energia mecânica em calor através do movimento do pneu por unidade de distancia percorrida.

LaClair [2] faz uma analogia sobre a relação entre resistência ao rolamento e o consumo de energia. Quando empurramos um carrinho de mão com pneu pouco inflado, percebe-se que é necessário um esforço extra para mantê-lo em movimento. A razão disso é que a resistência ao rolamento aumenta com a redução da pressão do pneu.

Assim, os pneus tem contribuição significativa no consumo de combustível. Em média, em veículos comerciais, a resistência ao rolamento dos pneus é responsável por aproximadamente $30 \%$ das forças dissipativas, contrárias ao movimento [3].

Para veículos comerciais, reduzindo $10 \%$ da resistência ao rolamento pode gerar uma economia de combustível entre $1,5 \%$ a $3,0 \%$ [4].

Os pneus para uso comercial é composto por aproximadamente 18 elementos diferentes, que se agrupam em sete grandes regiões. Na Figura 3, pode-se verificar a contribuição por cada uma dessas regiões na resistência ao rolamento.

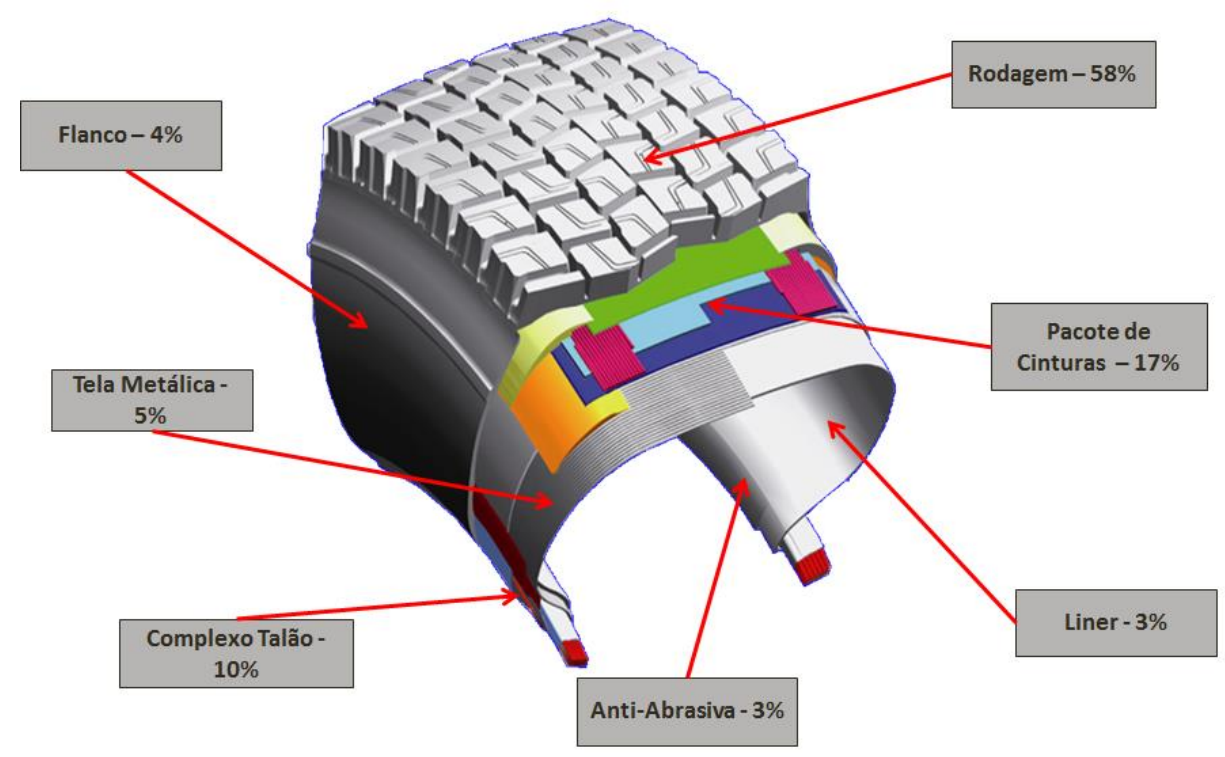

Figura 3 - Contribuição por região do pneu no RR

O teste para definição da classe de resistência ao rolamento do pneu é feito conforme descrito na norma técnica ISO 28580, realizado em um laboratório indoor em máquina especifica para tal ensaio. 


\section{O TESTE DE CONSUMO DE COMBUSTIVEL}

Para verificar efetivamente o ganho no consumo de combustível proveniente dos pneus, elaborou-se uma prova experimental baseada na norma SAE J1321. Esta norma, específica para caminhões e ônibus, estabelece critérios rigorosos para testes de consumo de combustível.

A prova foi realizada em uma pista de testes de formato oval com quatro quilômetros de extensão com o intuito de isolar/eliminar todos os demais fatores que influenciam no consumo de combustível como motorista, aerodinâmica, clima, percurso e outros.

Conforme a norma é obrigatório a utilização de dois veículos idênticos (cavalo + semirreboque) para a realização da prova. Um veículo de teste e outro veículo de referencia que permanece igual durante todos os ensaios. A diferença entre as cargas dos veículos dos ensaios era de $0,07 \%$, ou seja, praticamente inexistente.

Para eliminar a grande influência do motorista no consumo, ambos os veículos realizavam o teste com velocidade, marcha e rotação por minuto (RPM) iguais e constantes, sempre em piloto automático.

Para o teste, foram selecionados pneus da medida 295/80R22.5 e foram confrontados dois conjunto de pneus. Um conjunto com os pneus Pirelli FR:01 e TR:01 em confronto com pneus da concorrência de mesmo segmento e aplicação. Na Tabela 2, podemos verificar a diferença de valores de RR entre os pneus confrontados e a respectiva classificação de resistência ao rolamento dos mesmos conforme ISO 28580.

Tabela 2 - Diferença de RR entre os pneus em confronto e suas classificações

\begin{tabular}{|c|c|c|c|}
\hline Pneu & Classe de RR & $\begin{array}{c}\Delta \text { de RR entre os } \\
\text { pneus (\%) }\end{array}$ & Posição do pneu \\
\hline Pirelli FR:01 & C & $7 \%$ & $\begin{array}{c}\text { Eixo dianteiro cavalo } \\
\text { Semirreboque }\end{array}$ \\
\hline Dianteiro Concorrência & $\mathrm{D}$ & \multirow{2}{*}{$8 \%$} & Eixo traseiro cavalo \\
\hline Pirelli TR:01 & $\mathrm{D}$ & & \\
\hline Trativo Concorrência & & & \\
\hline
\end{tabular}


Para realizar a medição da quantidade de combustível consumido durante os ensaios, foram instalados em ambos os veículos um sistema de tanque auxiliar que era ativado através de botoeira localizada na cabine do veículo. Na Figura 4 abaixo, podemos verificar o tanque auxiliar localizado no chassi do veículo.

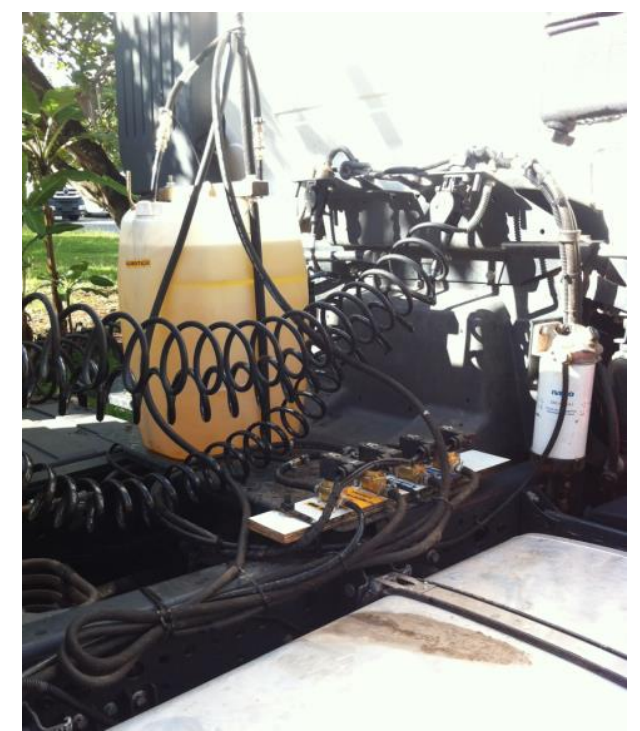

Figura 4 - Sistema de tanque auxiliar

Para fazer a medição da massa dos tanques auxiliares, antes e depois dos ensaios, foi utilizada uma balança de precisão com três casas decimais.

Seguindo as exigências da norma, para teste realizado em pista fechada é necessário realizar três passagens, cada uma com oitenta quilômetros. Após cada passagem, pesava-se o tanque auxiliar dos dois veículos para verificar a quantidade de combustível consumido durante a prova e calculava-se a relação deste consumo entre os veículos.

$\mathrm{Na}$ tabela abaixo, pode-se verificar a relação entre o consumo de combustível dos dois veículos (teste/controle) nas três passagens realizadas com cada conjunto de pneu.

Tabela 3 - Relação entre consumo do veículo de teste e o veículo de controle

\begin{tabular}{|c|c|}
\hline \multicolumn{2}{|c|}{ PIRELLI } \\
\hline Run & $\mathrm{T} / \mathrm{C}$ \\
\hline 1 & 1,0282 \\
\hline 2 & 1,0242 \\
\hline 3 & 1,0255 \\
\hline
\end{tabular}$\quad$\begin{tabular}{|c|c|}
\hline \multicolumn{2}{c|}{ Concorrente } \\
\hline Run & $\mathrm{T} / \mathrm{C}$ \\
\hline 1 & 1,0389 \\
\hline 3 & 1,0351 \\
\hline
\end{tabular}


Com base nestes resultados obtidos, calcula-se o ganho efetivo de economia de combustível entre os pneus analisados. Assim, verifica-se que o resultado obtido comprova que os pneus Pirelli apresentam uma economia de $\mathbf{1 , 1 2 \%}$ no consumo de combustível quando comparado com os pneus de concorrência em condições controladas.

\section{SIMULAÇÕES DOS ENSAIOS EXPERIMENTAIS EM SOFTWARE DE DINÂMICA VEICULAR}

Realizar ensaios experimentais de consumo de combustível em campo demanda um longo tempo e custos significativos. A alternativa estudada para reduzir os custos e tempos de avaliação das provas de consumo de combustível foi o uso do software de dinâmica veicular TruckSim ${ }^{\circledR}$ da Mechanical Simulation Corporation ${ }^{\circledR}$.

TruckSim® é uma ferramenta de software para simular e analisar o comportamento dinâmico de caminhões médios e pesados, ônibus e veículos articulados em respostas a ações de direção, frenagem e aceleração [5].

A alternativa pelo TruckSim® se deu pelo fato do mesmo possuir módulos que proporcionem a inserção de dados como curvas de consumo de combustíveis, curvas de torque, relação de marchas, relação de diferenciais e outras informações relevantes para medição do consumo de combustível, bem como a possibilidade de trabalhar com diferentes modelos de pneus e implementar modelos matemáticos externos de cálculo da resistência ao rolamento ou da força resistiva.

Para validação do modelo, além do modelo do veículo carregado, também foi necessário a modelagem da pista de provas.

3.1 Modelagem da pista de provas.

A pista onde foram realizados os testes experimentais foi modelada no TruckSim ${ }^{\circledR}$ usando a própria ferramenta de construção de pistas do software e utilizando dados fornecidos pela empresa responsável pela pista de testes. As principais características da pista são: Pista oval, asfalto, $4 \mathrm{~km}$ de extensão sendo duas retas com $7 \mathrm{~m}$ de largura e $1764 \mathrm{~m}$ de comprimento cada, com curvas inclinadas. 


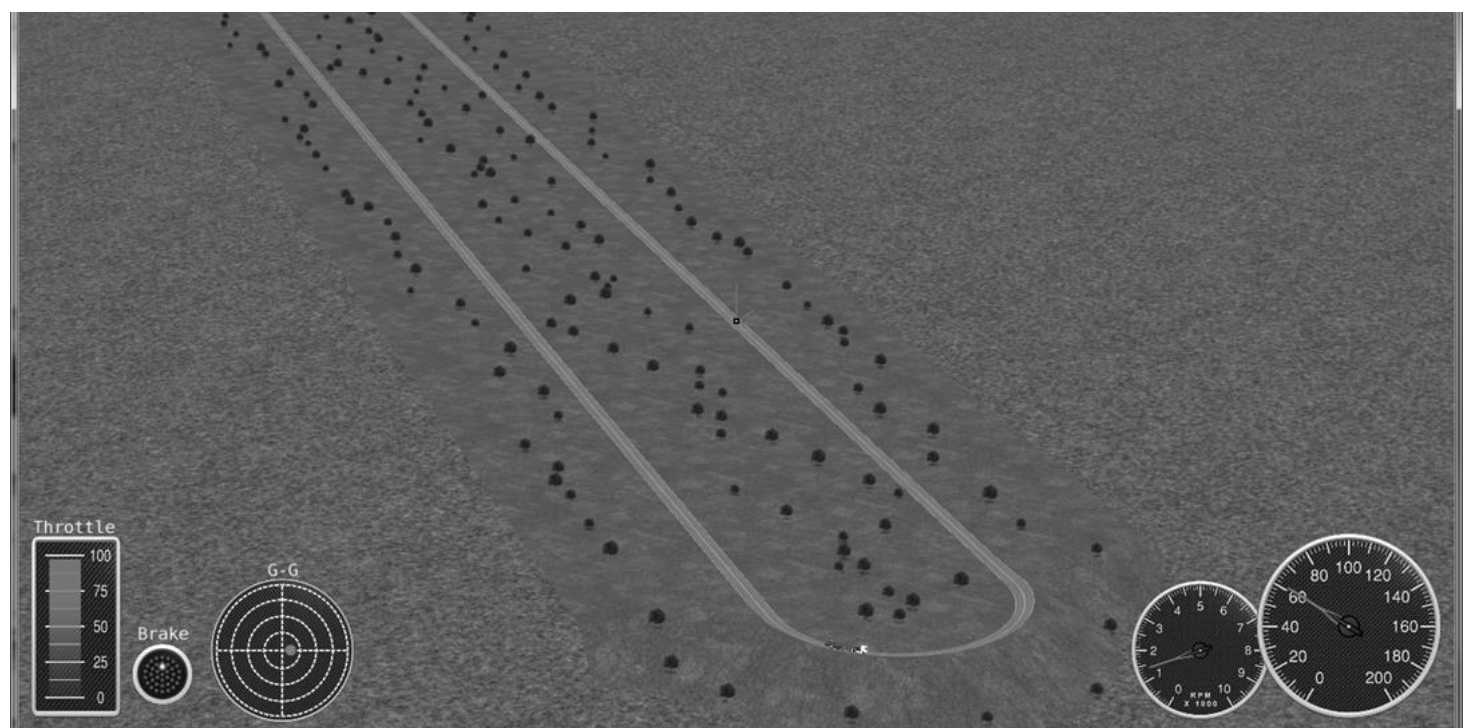

Figura 5 - Pista de testes Modelada no TruckSim ${ }^{\circledR}$ - [autor]

\subsection{Modelagem do veículo de teste}

Para início da modelagem do cavalo + semirreboque, foram considerados veículos e implementos que mais se aproximassem dos veículos reais. Para tanto, foi escolhido o modelo de cavalo mecânico do tipo S_SS (um eixo direcional + dois eixos trativos) com tração $6 \times 4$ e um semirreboque plano com 3 eixos de rodagem dupla "flatbed trailer".

A modelagem do veículo de teste foi feita de forma simplificada, todos os dados disponíveis foram utilizados, principalmente aqueles que têm maior influência no consumo de combustível.

Os dados dimensionais do veículo utilizado foram obtidos nas especificações técnicas fornecidas pela fabricante/montadora e inseridos no modelo virtual. Foram utilizadas as informações: largura máxima, comprimento máximo, altura máxima, distância entre eixos, bitola e posicionamento da quinta roda [6].

Os dados dimensionais do semirreboque foram obtidos através de medições experimentais e utilizados como dados de entrada para o modelo. Largura total, comprimento total, distancia entre eixos, posição do pino rei, bitola e altura da plataforma.

A simulação considerou o mesmo carregamento que o veículo testado, tendo o CG de sua carga posicionada de modo que distribuição da carga nos eixos do veículo simulado fosse equivalente a distribuição real em todos os eixos. 


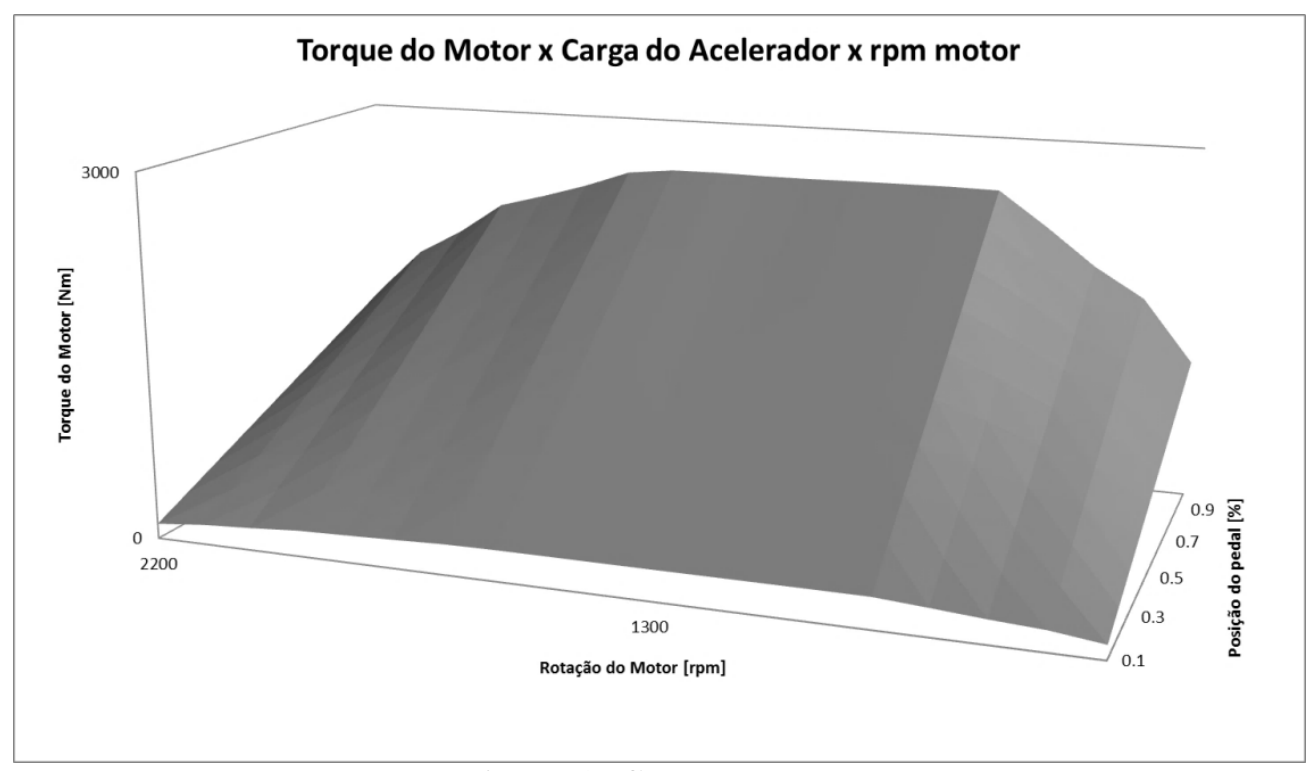

Figura 6 - Curva de torque do motor.

As informações sobre torque do motor (Figura 6) e consumo de combustível (Figura 7) foram fornecidas pela própria fabricante/montadora. Os dados foram fundamentais para correlação com os dados experimentais e validação do modelo de veículo.

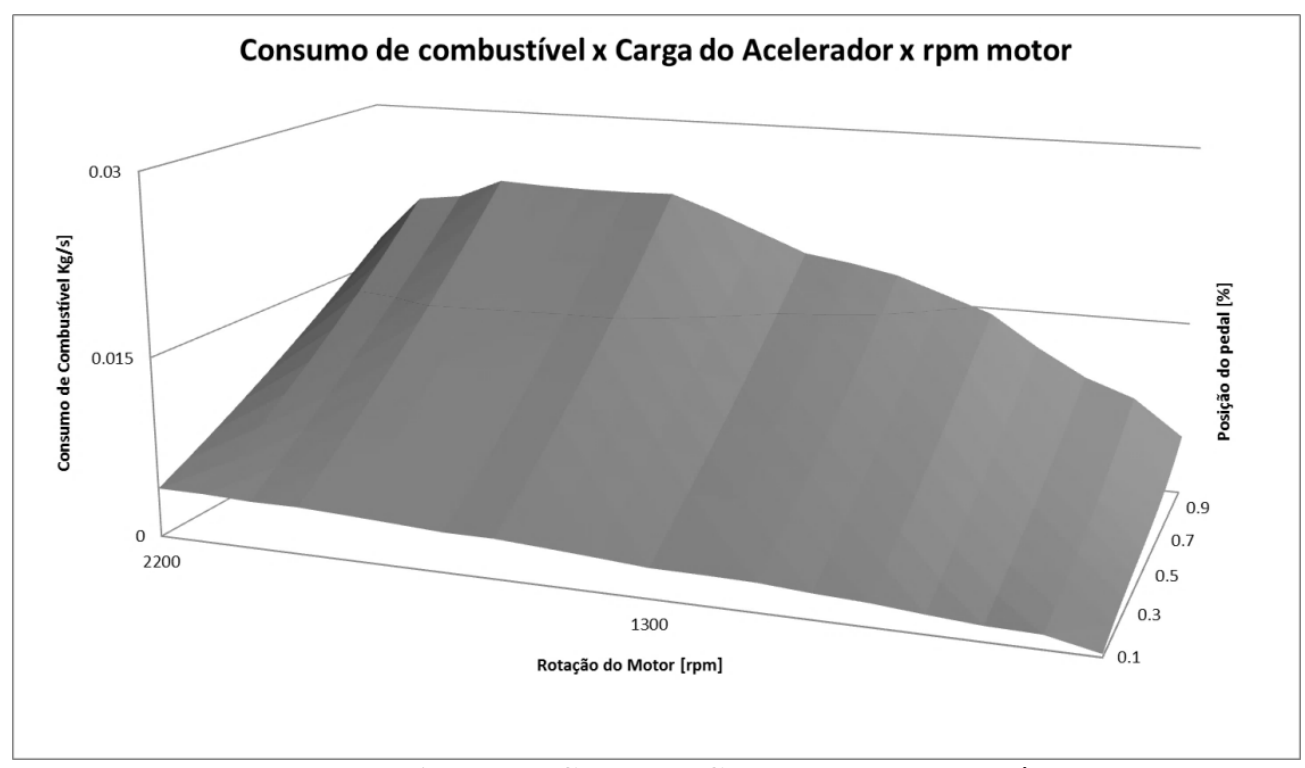

Figura 7 - Curva de Consumo de combustível. 


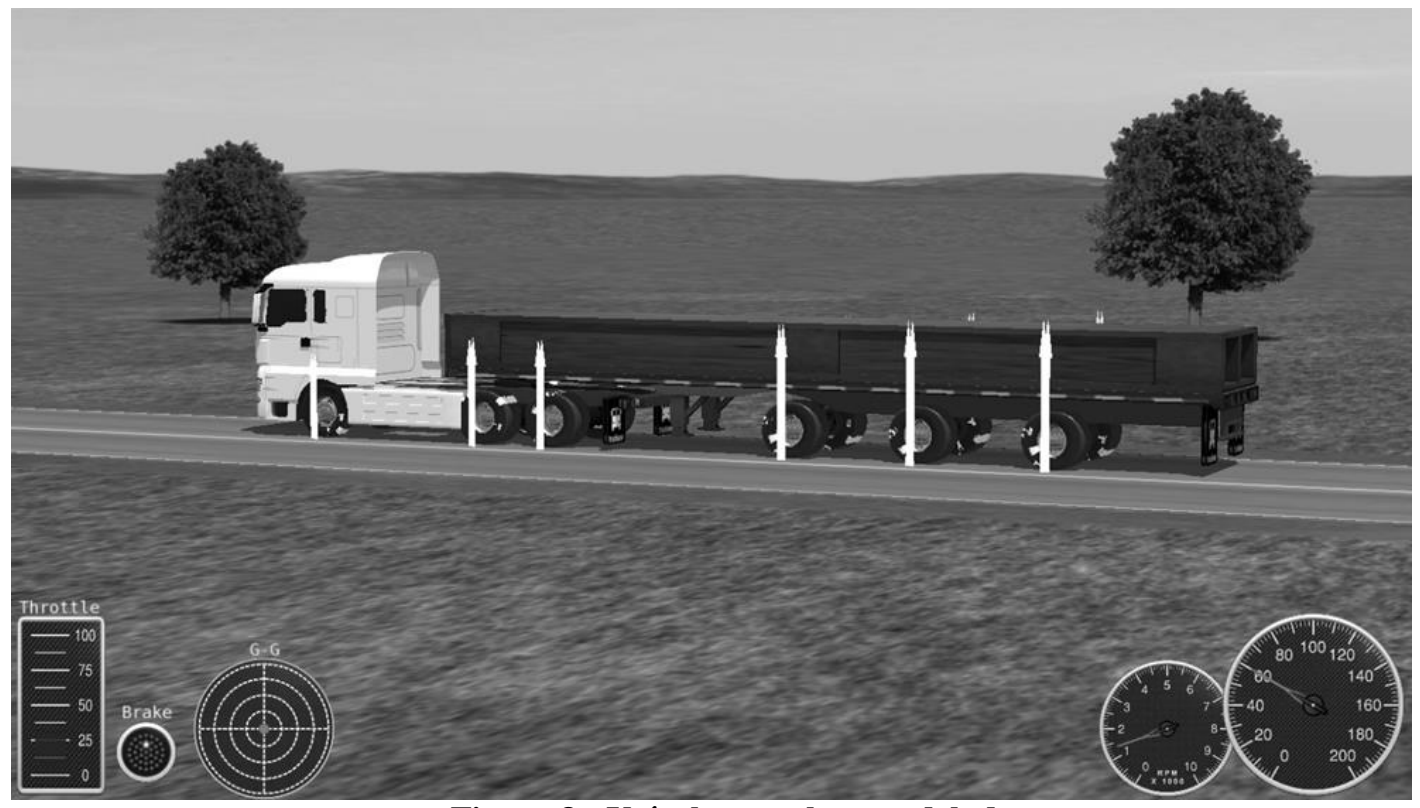

Figura 8 - Veículo completo modelado.

Com os dados disponíveis, foi possível a modelagem do veículo, como visto na Figura 8 , foi iniciado a modelagem dos pneus, onde consideramos como base o modelo de pneu do TruckSim ${ }^{\circledR}$, e corrigimos a rigidez vertical de cada pneu, e também inserimos a equação de resistência ao rolamento representativa de cada pneu.

\subsection{Modelamento dos pneus}

Os pneus foram separados em direcionais ( 2 na dianteira do cavalo mecânico e 12 na semirreboque ) - e trativos (8 nos eixos de tração do cavalo mecânico). Como os pneus direcionais e trativos possuem rigidez e resistência ao rolamento diferentes, os modelos foram gerados independentes.

Como o comportamento em dinâmica do veículo não é o foco do trabalho, as características do pneu usadas na modelagem foram as respectivas dimensões, rigidez e valor de RR. Na Figura

9 é possível ver a rigidez dos pneus Pirelli em Confronto com de nossos principais concorrentes, e notar que não existem diferenças significantes entre os mesmos. 


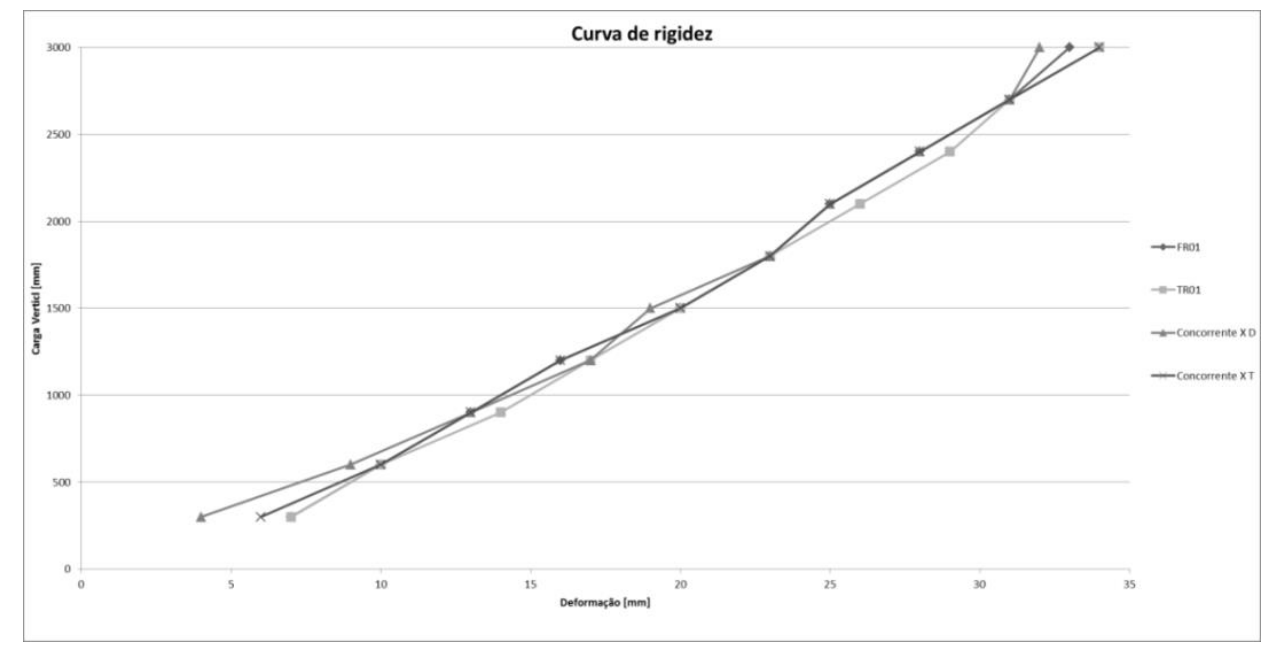

Figura

9 - Curva de Rigidez do pneu Pirelli e Concorrente

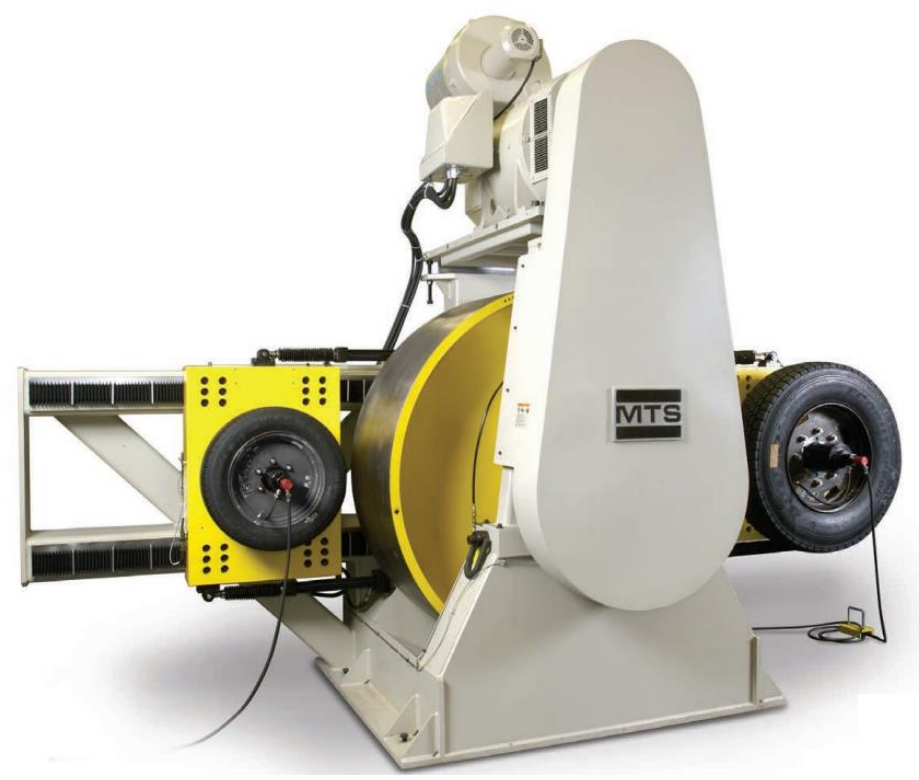

Figura 10 - Modelo de máquina para medição de Resistência ao Rolamento

Para a modelagem da resistência ao rolamento dos pneus, os mesmos foram testados em máquinas que medem a Força de resistência ao Rolamento, de acordo com a metodologia SAE J1269 nas condições abaixo, o que originou o gráfico da Figura 1111.

Pressão de Inflação: de $0.62 \mathrm{MPa}$ até $1.00 \mathrm{MPa}$

Carregamento Vertical: $3924.0 \mathrm{~N}$ até $40221.0 \mathrm{~N}$ 


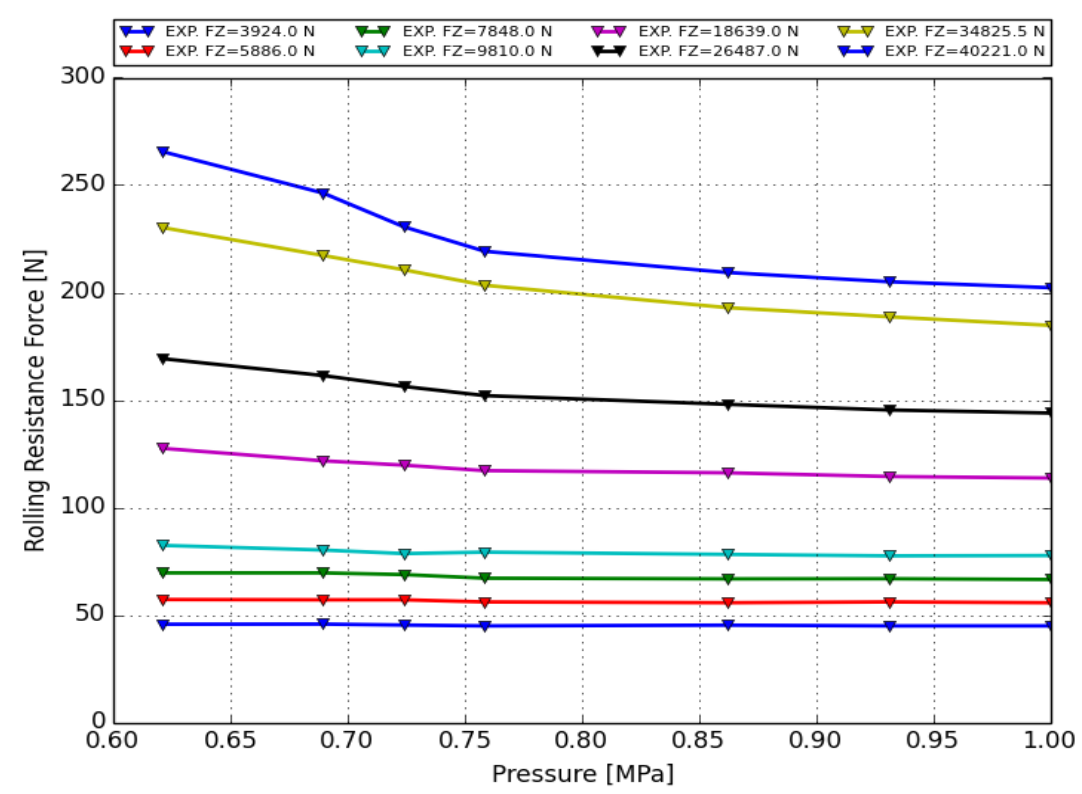

Figura 11 - Gráfico Força Resistência ao rolamento x Pressão de Inflação em diversos carregamentos verticais

A publicação da SAE J1269[7] recomenda práticas de testes experimentais para serem aplicados na medição de resistência ao rolamento e propõe a seguinte equação para utilização em pneus Light Truck, onde " $F_{R R}$ " é a Força de Resistência ao rolamento, " $F z$ " é a Carga Vertical e " $p$ " a pressão de inflação.

$$
F_{R R}=a_{0}+a_{1} F_{z}+a_{2} \frac{1}{p}+a_{3} \frac{F_{z}}{p}+a_{4} \frac{F_{z}}{p^{2}}
$$

Com os dados do gráfico acima e a Error! Reference source not found., foi criada uma metodologia interna que faz o ajuste dos coeficientes para melhor representação dos dados experimentais e desenvolvida uma nova equação, a partir da Equação (1) que melhor represente a força resistiva do pneu sobre diversas condições de carga e pressão de inflação.

As equações geradas foram implementadas no software de dinâmica veicular TruckSim ${ }^{\circledR}$ para cada pneu avaliado: Pirelli Dianteiro, Pirelli Trativo, Concorrente X Dianteiro e Concorrente X Trativo.

Esse método permite que o modelo matemático do software calcule a força de resistência ao rolamento para cada condição operacional, individualmente, e no domínio do tempo. Desse modo, podemos ter a força de resistência ao rolamento em situações dinâmicas, sendo influenciada por transferências de cargas laterais e longitudinais. 
3.4 Resultados simulados

A simulação do modelo seguiu as mesmas condições do teste experimental, ou seja, velocidade, marcha e rotação por minuto (RPM) constante.

Na simulação, o modelo percorreu $10 \mathrm{~km}$ em regime constante, desconsiderando o período de aceleração, e foi medida a massa de combustível consumida durante a prova, necessária para percorrer a distância estipulada.

O resultado pode ser visto na tabela abaixo, onde podemos notar que o modelo feito no software de dinâmica veicular apresentou resultados bastante alinhados com a realidade, principalmente se considerarmos as condições de contorno consideradas.

\begin{tabular}{|l|l|l|}
\hline & Experimental & Simulado \\
\hline Pirelli & $\mathbf{1 0 0 \%}$ & $\mathbf{1 0 0 \%}$ \\
\hline Concorrente X & $101.12 \%$ & $100.91 \%$ \\
\hline
\end{tabular}

O resultado mostrado na tabela acima possibilitou validar o modelo e a simulação, ratificando o quanto o veículo equipado com pneu da concorrência consome a mais de combustível, cerca de $1 \%$, ao final dos $10 \mathrm{~km}$ simulados na pista oval.

\section{CONCLUSÃO}

O ensaio foi realizado com sucesso dentro dos parâmetros da norma internacional SAE com resultado estatisticamente significativo e confiável, conforme cálculos indicados na norma. Assim, o resultado obtido comprova que os pneus Pirelli apresentam um ganho de $1,12 \%$ no consumo de combustível quando comparado com os pneus de concorrência em condições controladas, mostrando um resultado alinhado com os valores obtidos em laboratório indoor.

A reprodução do teste via software foi satisfatório quando comparados aos resultados obtidos nos testes experimentais realizados, podendo ser uma ferramenta de desenvolvimento e estudos confiável viabilizando resultados mais ágeis e com custo inferior quando comparado aos testes experimentais. 


\section{REFERÊNCIAS}

[1] Schuring, D.J., 1977, "A New Look at the Definition of Tire Rolling Loss," Tire Rolling Losses and Fuel Economy-an R\&D Planning Worshop, SAE Conf. Proc. P-74, 31-37

[2] T. J. LaClair, "Rolling Resistance," in The Pneumatic Tire, National Highway Traffic Safety Administration, 2006, pp. 475-532.

[3] Barrand, J. and Bokar, J., " Reducing Tire Rolling Resistance to Save Fuel and Lower Emissions," Presented at SAE World Congress and Exhibition, SAE 2008-01-0154, Detroit, MI, 2008.

[4] D. J. Schuring, Tire Science and Technology, pp. 22-23, 1988.

[5] Mechanical Simulations, TruckSim. Website. Disponível em http://carsim.com/products/trucksim/index.php. Acesso em: 19/05/2015

[6] Iveco Brasil, website Disponível em: http://www.iveco.com/Brasil/collections/technical_sheets/Documents/iveco_hiway_800S44TZ_800S48TZ_800S56TZ_6x4_03062014.pdf . Acesso em: 19/05/2015

[7] SAE J 1269, Rolling Resistance Measurement Procedure for Passenger Car, Light Truck, and Highway Truck and Bus Tires. 18/09/2016. 